\section{Not only gone with the wind}

Peter D. Moore

THE value of detailed study of apparently well-defined ecological processes is evident in new work reported in Ecology ${ }^{1}$ by S. B. Vander Wall. He shows that even among seeds (such as those of pine) regarded as winddispersed on the basis of their morphological structure, secondary dispersal by animals can be crucial to effective seed dissemination, and to ultimate germination and establishment.

Population mobility is a valuable asset to a species, especially under conditions of rapid environmental change when the suitability of a given habitat may alter. Among mobile species, the problems to be faced are mainly those of overcoming physical barriers, but for most plants population movement depends also on the efficiency of fruit or seed dispersal. In studying this aspect of plant population biology, many ecologists have been content with relatively simple analyses of dispersal mechanisms, often classifying them into a series of types (wind, water, animal vectors and so on). But careful examination of individual cases, such as that described by Vander Wall, demonstrates that the real world is more complicated than that.

The involvement of animals in the secondary dispersal of seeds is by no means a novel observation. In violets (Viola species), for example, animals are often implicated in this second stage ${ }^{2}$. Initial dispersal is usually effected by a violent explosion of the fruit as the drying capsule splits into three elastic valves and ejects the ripe seeds.

\section{Scatter}

Although this results in a scatter of seeds only tens of centimetres from the parent plant, it does at least take the new generation out of the immediate influence of the old. The seeds of many species, however, are invested with a caruncle containing oily material that is much prized by ants, which gather the seeds and transport them to their nests. After consuming the caruncle (which does not damage the seed embryos), the remainder of the seed is discarded and may subsequently germinate. A twostage dispersal of this kind raises the question of whether the plant may be better served by missing out the first (relatively inefficient) stage and so give the ants a better chance of finding the entire, seed-packed capsule, rather than having to forage for scattered individual seeds. On the other hand, the initial explosive dispersal can provide a useful backup in the event of the failure of the ant-mediated stage.

A similar double strategy dispersal has been described by Janzen ${ }^{3}$ for guanacaste tree seeds (Enterolobium cyclocarpum) in Costa Rica. Here the seeds are consumed initially by horses and pass unharmed through the gut to be deposited in the faeces. The collections of seeds in dung piles are then the focus of the foraging activity of a seed-eating

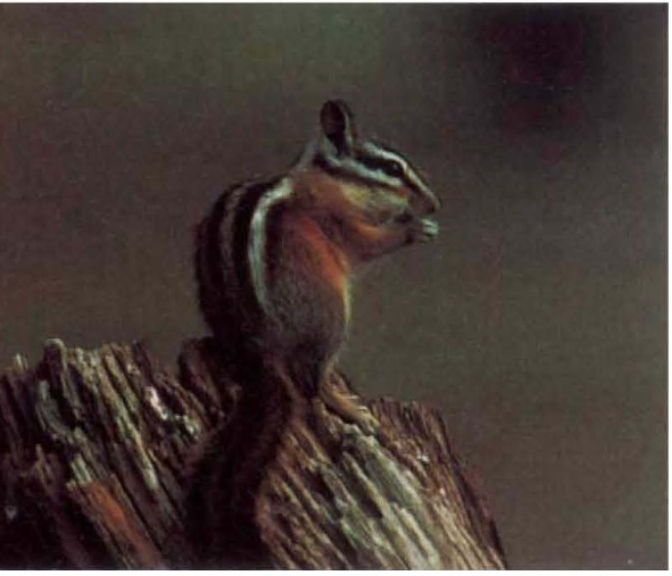

yellow pine chipmunk, an agent of seed dispersal.

rodent, the spiny pocket mouse (Liomys slavini), which caches seeds in its tunnels, and Janzen has been able to show experimentally that seeds are more effectively harvested by the mouse from scattered small (2-litre) dung piles than from large (8-litre) ones. This dispersal process has the advantage over that of Viola, in that even the first stage is efficient in terms of distance travelled, but the seeds are still deposited in groups and are thus more easily harvested by foraging rodents. The relative value of what Howe ${ }^{4}$ has termed "clump" and "scatter" syndromes in the dispersal of seeds is evidently related to whether or not a secondary vector is involved in the final disposition of the propagules.

Following the movements of individual seeds during dispersal, especially secondary dispersal by animal vectors, presents many practical problems, and Vander Wall ${ }^{1}$ has used radioactive isotopes in his studies of the Jeffrey pine (Pinus jeffreyi) in Nevada. Using seeds soaked in scandium-46 (a $\gamma$-emitter with a half-life of 84.5 days), he laid out groups of eight seeds at different distances from a pine tree, simulating densities expected from wind dispersal and extending out to $12 \mathrm{~m}$ from the tree. Each seed was marked with its source location and the experiments were run for between two and five days, after which the seeds were relocated using a $\gamma$-radiation detector. Yellow pine chipmunks, together with other small mammals, had been observed gathering pine seeds in the area, and it turned out that over 95 per cent of the experimental seeds disappeared over the test period. With the aid of the detector, 128 caches of seeds were found in chipmunk tunnels, accounting for 54 per cent of the lost seeds.

\section{Distance}

Whereas the wind-dispersal model predicted that most seeds would fall within $12 \mathrm{~m}$ of the tree, some caches, the contents of which ranged from 1-13 seeds, were found at distances of over $60 \mathrm{~m}$. The wind model does not allow for high wind speeds, which could permit wider dispersal, but it was realistic in its prediction that seeds would be concentrated close to the source tree. The secondary dispersal in this case is effective in extending the mean dispersal distance of seeds, thereby increasing the likelihood that seeds would be deposited in suitable locations away from the immediate shade of their parent.

A further beneficial effect of the secondary dispersal is the burial of the seeds. In an experiment designed to determine the comparative effects of burial and superficial deposition, rodents were excluded from certain areas and some seeds were left on the surface while others were buried in a manner intended to simulate the activity of chipmunks. The following spring, the only surface-deposited seed to germinate was one that had subsequently been buried by ants. All the remainder failed to germinate, whereas 55 per cent of the buried seeds produced a seedling. It seems that the pine gains not only from the additional dispersal provided by a secondary rodent vector, but also by the treatment received at the paws of this mammalian agent. Obviously, many of the seeds in such caches will be consumed by the chipmunks, but occasional chipmunk death or forgetfulness means that a significant proportion survive to germinate another day.

Peter D. Moore is in the Division of Biosphere Sciences, King's College London, Campden Hill Road, London W8 7AH, UK.

\footnotetext{
1. Vander Wall, S. B. Ecology 73. 614-621 (1992). 2. Beattie, A. J. \& Lyons, N. Am. J. Bot. 62, 714-722 (1975).

3. Janzen, D. H. Ecology 63, 1887-1900 (1982).

4. Howe, H. F. in Reproductive Ecology of Tropical Forest Plants (eds Bawa, K. S. \& Hadley, M.) 191-218 (Parthenon, Park Ridge, New Jersey, 1990).
} 